\title{
IMPROVEMENT OF ALGORITHM FOR ASSESSING EFFICIENCY OF AUTOMATIC INFORMATION AND TELECOMMUNICATION SYSTEMS FUNCTIONING FOR TRAFFIC MONITORING
}

\author{
Muhtar Kerimov $^{1}$, Irina Belinskaia ${ }^{2}$, Galina Bulgakova ${ }^{1}$ \\ ${ }^{1}$ Saint-Petersburg State Agrarian University, Russia; \\ ${ }^{2}$ Leningrad State University named after Alexander Pushkin, Russia \\ kerimofmuhtar@yandex.ru, belinska@yandex.ru, bulgakova1@mail.ru
}

\begin{abstract}
One of the ways to improve the efficiency of transport systems is the introduction of continuous monitoring of the machines operation and their operating conditions. The most promising area of research in the subject area is the development and use of intelligent transport systems. Such systems enable intelligent interaction with single vehicles or with the traffic flow as a whole through information and telecommunication technologies in order to increase the efficiency of land transport and improve road safety. The process of creation and application of automatic information and telecommunication systems for monitoring the movement of vehicles is usually associated with the problem of assessing their effectiveness. The article presents a model for evaluating the effectiveness of automatic information and telecommunication systems for monitoring the movement of vehicles, which allows to quantify the effectiveness of their application. A feature of these systems is their service nature. The technique of optimal application of technical means of control in the field of road safety in the operation of the system "driver-car-road" is presented. The results of the study of the various factors influencing determining the number of road accidents in the Russian Federation region are presented. The criteria of functioning efficiency of automatic systems of vehicle movement control taking into account the probabilistic nature of system-forming factors are offered. The perspective directions of the control function at operation of vehicles on the basis of use of the systems of automatic control are proved. The scheme of development of multipurpose systems of automatic control of vehicle movement is presented.
\end{abstract}

Keywords: vehicles, control systems, efficiency, probabilistic approach, system analysis.

\section{Introduction}

The process of creating and using automatic information and telecommunication systems for controlling the movement of vehicles is usually associated with the problem of evaluating their effectiveness. This raises a number of complex issues, due to the specifics of the problems for which this object is designed. For example, road safety ensuring is a problem task to be solved at the state level. One of the criteria for the transition to a new level in the development of transport systems is the widespread introduction of continuous monitoring of machines functioning and their operating conditions. The most promising direction of scientific research in the subject area under consideration is the development and use of intelligent transportation systems (ITS). Such systems provide the possibility of intellectual interaction with single vehicles or with the transport flow as a whole through the means of information and telecommunication technologies with the aim of increasing of land transport using effectiveness and improving road safety [1]. The practice of setting scientific and technical problems and making management decisions in the subject area under study indicates the need to take into account the hierarchy of the road and transport systems structure and the technologies implemented in them, characteristics variability of the road network through the time, the technical parameters of vehicles and, as a rule, the probabilistic nature of the functioning conditions [1-3].

\section{Materials and methods}

In accordance with the system methodology, photo and video recording complexes should be presented as a set of intersections of the following systems:

- technological structure (infrastructure facility);

- technological manufacturing system (assembly);

- systems "infrastructure facility - operators";

- technical maintenance and repair systems;

- system "infrastructure facility - the environment";

- system "infrastructure object - vehicle". 
To assess the effectiveness of photo and video recording functioning of administrative offenses in the road and transport sphere when interacting with objects of the i-th system, it is advisable to use the criterion $K_{e i}$ [4-6]

$$
K_{\ni i}=\frac{\left\{E(+)_{i j}\right\} \cdot\left\{I_{i j}\right\}}{\left\{C_{s i j}\right\} \cdot\left\{\ni(-)_{i j}\right\}},
$$

where $\{Э(+)\},\{Э(-)\}-$ a set of, respectively, positive and negative effects of the complex functioning at the considered stage. From a system point of view, a positive effect is characterized by an increase in road safety, and a negative effect is a decrease in road safety and, accordingly, an increase in traffic accidents with all the ensuing consequences;

$C_{s i j}$ - set of system costs for the operation of the complex and maintaining it in a technically sound condition, reduced to the form of an economic indicator;

$I_{i j}$ - set of entropy types of the system neutralized by the (SAF), i.e. reducing of road traffic accident level, presented in the form of an economic indicator [7-8].

In such tasks, entropy means the process of energy consumption, for example, the cost of living labor, amortization of equipment, etc. In our case, this is damage caused by a traffic accident. In the above set of systems (1), criteria $1 \ldots 4$ correspond to the comparative indicators of the quality functioning considered by SAF in the road and transport sector. The rest criteria (5 and 6) are of a regulatory nature as, respectively, indicators of environmental and aesthetic feasibility. Analytical dependencies between individual system-forming factors, as well as technical, technological, and space-time constraints taken into account in the operation of the driver-car-road system, are presented in the works of the authors [3-5;9-16].

\section{Results and discussion}

The task of assessing of SAF functioning effectiveness is multicriterial. To solve it a certain technique is often used that involves ranking all the criteria presented. In this formulation, the importance of each criterion should be determined by the degree of its impact on society (increased road safety) and evaluated by an objective indicator -by the influence rank of the $\mathrm{j}$-th private direction of optimization relative to the most foreground option $\left(C_{1}\right)-R_{S j / C 1}$. Then the efficiency of the optimization resource usage and aesthetic expediency (compliance of the complexes with the applicable standards) can be assessed by the dependence:

$$
f_{01 t, \Sigma}=\left\{\begin{array}{l}
\sum_{i=1}^{n_{T K}}\left[K_{\ni \phi i C_{1}} \rightarrow\left\{1-\sum_{j=2}^{4} R_{S C_{j} / C_{1}}\right\}\left(\max _{C_{1}}\right)\right] \\
K_{э \phi C_{2}} \rightarrow R_{S C_{2} / C_{1}} \cdot R_{\alpha C_{2}}\left(\max _{C_{2}}\right) \\
\sum_{i=1}^{n_{o n}}\left[K_{\ni \phi i C_{3}} \rightarrow R_{S C_{3} / C_{1}} \cdot R_{\alpha C_{3}}\left(\max _{C_{3}}\right)\right] \\
K_{э \phi i C_{4}} \rightarrow R_{S C_{4} / C_{1}} \cdot R_{\alpha C_{4}}\left(\max _{C_{4}}\right)
\end{array}\right\},
$$

where $\quad n_{T K}, n_{o n}$ - respectively, the number of communication channels with functional objects and operators;

$R_{\alpha C i}$ - indicator characterizing the usage efficiency of the optimization resource in the i-th direction.

As optimization resources, various circuit solutions are considered, involving the use of mobile and stationary photo and video recording systems, the choice of their location, etc. The rank of the social influence of the $\mathrm{i}$-th direction (level of accident rate reduction) optimization is determined by the following relationship:

$$
R_{S C_{i}}=\frac{N_{S C_{i}} \cdot \eta_{S C_{i}}}{N_{S C_{1}} \cdot \eta_{S C_{1}}}(3),
$$


where $N_{S C i}-$ size of the social group that is affected by the effectiveness level of the $i$-th SAF functioning;

$\eta_{S C i}$ - specific share of the effectiveness level impact of the $i$-th SAF system functioning on the interests of a social group member:

$$
\eta_{S C_{i}}=\frac{V_{\Delta K_{\supset \phi C_{i}}}^{j}}{\sum V^{j}}
$$

where $j$-determining influence factor (economic, social, etc.);

$\Sigma V^{j}-$ set of impacts to reduce accidents during the implementation of $\mathrm{j}$-events (for example, for a year).

These impacts are implemented through economic indicators: $V_{\Delta \ni \phi C i}^{j}-$ volume of impacts, depending on the effectiveness level of the SAF system functioning; $N_{S C i}$ - numerical force of the social group; $\eta_{S C i}-$ specific share of the impact of technological action of optimization trend for which $R_{S C i}=1$. Quantitative assessment of the influence factors is determined by expert polls [17]. In this study, from the standpoint of the system approach, a model of the influence of various factors on functioning of the automatic fixation system of traffic violations is presented (Fig. 1), at the input of which a vector function of the monitored parameters acts $\bar{X}$. This group of factors includes the geometric characteristics of the road network sections and the characteristics of traffic flows.

Another set of inputs represented by a vector function $\bar{E}$ includes factors that take into account the technical and operational characteristics of objects on the street road network (SRN) and data on traffic violations by road users. The vector function of unmanaged parameters $\bar{B}$ is interpreted as an additive interference of a probabilistic nature. These parameters include road conditions, driver skills, etc. The causal relationship between these system-forming features is modeled by the following relationship: $Q=A|X, B, E|$, where $Q$ is the criterion for evaluating the SAF functioning.

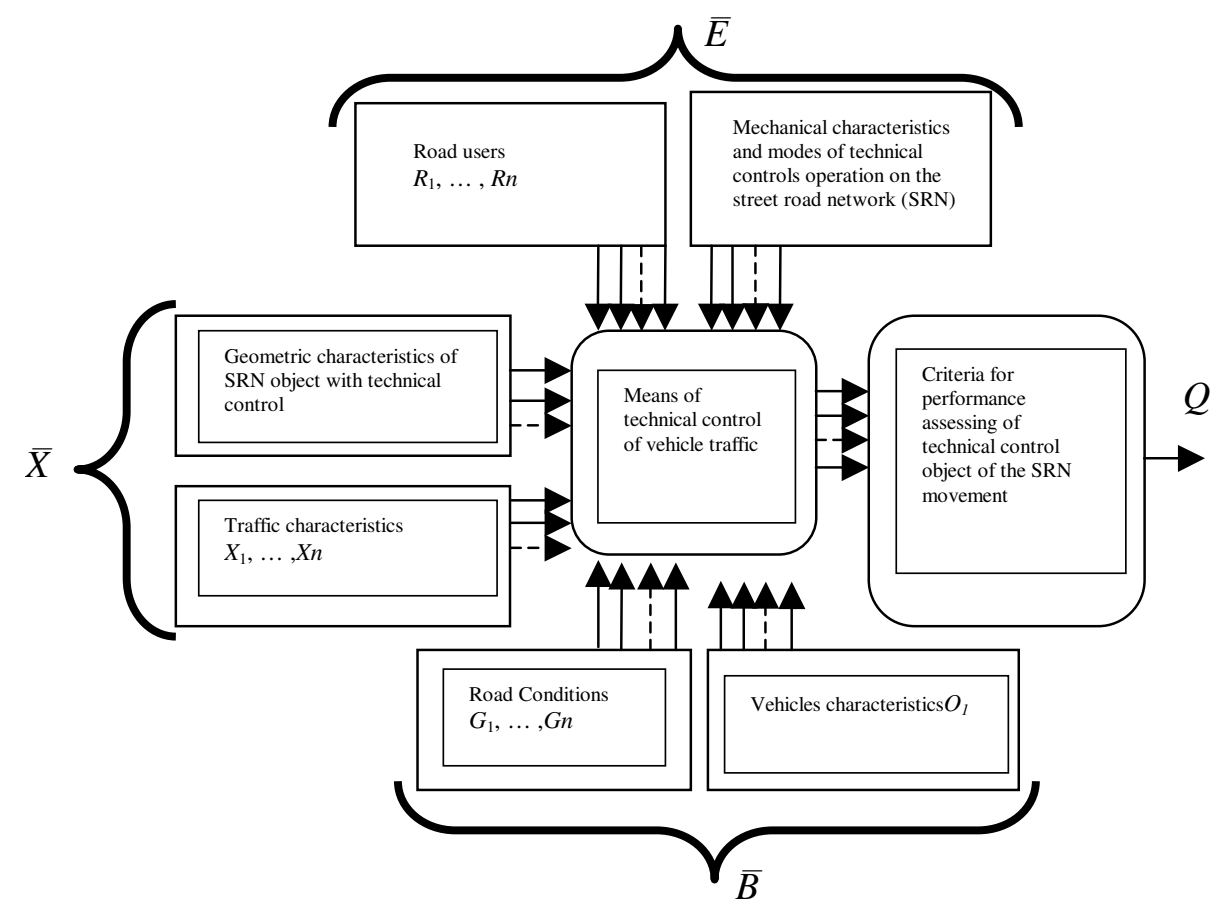

Fig. 1. Model of factor influence on motion control system functioning

The functioning of the system of automatic photo-video recording of traffic rules violation covers several stages, the totality of which is called its life cycle. In the general case, the term "life cycle" refers to a certain evolution, a period of time and a set of activities that change the state of the system under consideration from the start of operation to the end of its operation [18]. 
To implement a systematic approach to assessing the effectiveness of the SAF research stages are proposed [2]. It includes definition of the baseline data, assessment of the SAF impact on the traffic safety on absolute and indirect parameters (number of decisions on administrative offenses, the number of photo-video recording complexes etc.).

In order to assess the impact of various factors on the number of road accidents in the Russian Federation regions, multiple regression analysis was performed. The factors taken:

- indicator characterizing the ratio of the number of vehicles to the number of decisions on administrative offence $\left(x_{1}\right)$, vehicle per unit;

- amount of fines paid $10^{5}\left(x_{2}\right)$, rubles;

- number of stationary $\operatorname{SAF}\left(x_{3}\right)$, unit;

- number of portable SAF $\left(x_{5}\right)$, unit;

- number of mobile $\operatorname{SAF}\left(x_{6}\right)$, unit;

- presence of a sign on the SAF action $\left(x_{7}\right)$, unit;

- density population in the region $\left(x_{8}\right)$, people $\cdot \mathrm{km}^{-2}$;

- density transport in the region $\left(x_{9}\right)$, unit $\mathrm{km}^{-2}$;

- length of roads $\left(\left(x_{10}\right), \mathrm{km}\right.$;

- region population $\cdot 10^{6}\left(x_{11}\right)$, people;

- region territory $\left(x_{12}\right), \mathrm{km}^{2}$;

- number of vehicles in the region $\left(x_{13}\right)$, unit.

The accident rate is the system parameter $Y$, which characterizes the number of accidents. To analyze the relationship between the parameters under consideration, we used statistical data for 2017 obtained in the studied regions: Moscow, Moscow region, Saint-Petersburg, Leningrad region, the Republic of Tatarstan, Voronegh retion, Saratov region (Table 1).

Table 1

Statistical data characterizing the impact of various factors on road safety

\begin{tabular}{|c|c|c|c|c|c|c|c|}
\hline Factors & $\begin{array}{c}\text { Voronegh } \\
\text { region }\end{array}$ & Moskow & $\begin{array}{c}\text { Moskow } \\
\text { region }\end{array}$ & $\begin{array}{c}\text { Saint- } \\
\text { Petersburg }\end{array}$ & $\begin{array}{c}\text { Leningrad } \\
\text { region }\end{array}$ & $\begin{array}{c}\text { The } \\
\text { Republic of } \\
\text { Tatarstan }\end{array}$ & $\begin{array}{c}\text { Saratov } \\
\text { region }\end{array}$ \\
\hline Accidents & 3555 & 11312 & 9042 & 8222 & 4074 & 5399 & 3101 \\
\hline$x_{1}$ & 3.62 & 12.23 & 5.9 & 1.76 & 1.13 & 7.82 & 0.99 \\
\hline$x_{2}$ & 1127.65 & 5490.53 & 1100.32 & 329.66 & 255.88 & 2892.65 & 224.65 \\
\hline$x_{3}$ & 39 & 708 & 186 & 66 & 66 & 201 & 26 \\
\hline$x_{4}$ & 62 & 301 & 15 & 22 & 22 & 296 & 49 \\
\hline$x_{5}$ & 1 & 5 & 0 & 0 & 0 & 0 & 0 \\
\hline$x_{6}$ & 1 & 0 & 8 & 0 & 0 & 17 & 1 \\
\hline$x_{7}$ & 38 & 70 & 89 & 75 & 75 & 39 & 42 \\
\hline$x_{8}$ & 44.6 & 4822.1 & 160.7 & 3566.7 & 21.02 & 56.57 & 24.66 \\
\hline$x_{9}$ & 13.72 & 261.5 & 18.22 & 521.63 & 8.13 & 9.14 & 6.73 \\
\hline$x_{10}$ & 11602 & 737 & 27229 & 531 & 13662 & 22267 & 11799 \\
\hline$x_{11}$ & 2.33 & 13.11 & 7.33 & 5.13 & 1.7 & 3.84 & 2.5 \\
\hline$x_{12}$ & 52216 & 2511 & 44379 & 1439 & 83008 & 67847 & 101240 \\
\hline$x_{13}$ & 716388 & 656766 & 808847 & 750623 & 682385 & 620688 & 681453 \\
\hline
\end{tabular}

As it can be seen from Table 1, the factors $x_{9}, x_{10}$ and $x_{12}$ have the maximum impact on accident rates. The greatest influence is from the factor $x_{11}$, , on which $88.4 \%$ depends on the number of accidents.

According to the program Statgraphics analysis was performed of the influence of the factors $x_{8}$, $x_{9}$ and $x_{11 .}$ (Table 2). 
Statistic characteristics of mathematic model

Table 2

\begin{tabular}{|c|c|c|c|c|}
\hline Parameter & Estimate & $\begin{array}{c}\text { Standard } \\
\text { Error }\end{array}$ & $\boldsymbol{T}$-statistic & $\boldsymbol{p}$-value \\
\hline Constant & 1326.05 & 698.759 & 1.89772 & 0.1540 \\
\hline$x_{8}$ & -1.09546 & 0.528357 & -2.07333 & 0.1298 \\
\hline$x_{9}$ & 10.5527 & 3.81843 & 2.76361 & 0.0699 \\
\hline$x_{11}$ & 1033.04 & 172.974 & 5.97221 & 0.0094 \\
\hline
\end{tabular}

The mathematical model is defined as:

$$
y=1326.05-1.09546 x_{8}+10.5527 x_{9}+1033.04 x_{11} .
$$

According to the degree of influence the factors have the following hierarchy: $x_{8}, x_{11}, x_{9}$. The influence of $x_{1}, x_{2}, x_{3}$ and $x_{8}$ factors on road accidents is modeled by dependence:

$$
\mathrm{y}=2379.24+1543.63 x_{1}-3.9134 x_{2}+9.4035 x_{3}+1.0307 x_{8} .
$$

The statistical characteristics of the model are presented in Table 3.

Statistical characteristics of the model

Table 3

\begin{tabular}{|c|c|c|c|c|}
\hline Parameter & Estimate & $\begin{array}{c}\text { Standard } \\
\text { Error }\end{array}$ & $\boldsymbol{T}$-statistic & $\boldsymbol{p}$-value \\
\hline Constant & 2379.24 & 377.889 & 6.29614 & 0.0243 \\
\hline$x_{1}$ & 1543.63 & 193.139 & 7.99232 & 0.0153 \\
\hline$x_{2}$ & -3.91341 & 0.472106 & -8.28924 & 0.0142 \\
\hline$x_{3}$ & 9.40355 & 3.09578 & 3.03754 & 0.0934 \\
\hline$x_{8}$ & 1.0307 & 0.153725 & 6.70487 & 0.0215 \\
\hline
\end{tabular}

The analysis of the obtained model shows that the main contribution to the accident rate is made by the number of registered vehicles in a particular region $-x_{1}$. This factor is taken into account in the model through the normative indicator - the number of vehicles per one photo-video recording device. The recommended provision of the region with means of automatic photo-video recording is one complex for 6.5 thousand registered vehicles [19;20].

At each stage of the life cycle of a system, a specific set of tasks arises and the most optimal methods for their implementation are determined. In this case, for each stage, the initial are the circuit solutions adopted at the previous iteration.

Also for each stage the objectives and goals of their application should be changed, as well as the functionality of these complexes should be changed. In this regard, further development of the interaction of the SAF with intelligent on-board vehicle systems [21-23] is of great importance. To improve information exchange between intelligent onboard transport systems and automatic photo and video recordings, an information analysis system (IAS) was proposed and recommendations for its development were designed.

Information-analytical system of interaction between IBTS and automatic photo and video recordings allows to ensure efficient use of PBXs, improve traffic safety, solve social problems of transport operations and reduce environmental pressures by expanding the functionality of the SAF $[19 ; 24 ; 25]$.

The scheme of interaction of this system with the vehicle is shown in Fig. 2. 


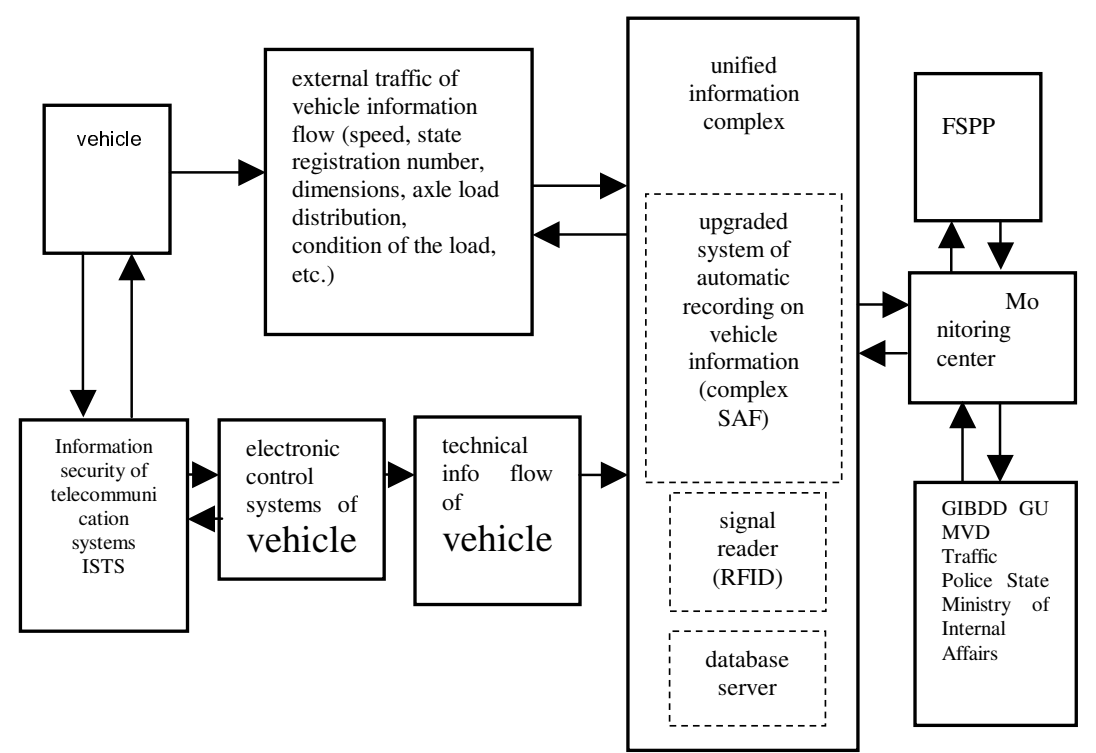

Fig. 2. Scheme of interaction between information-analytical system and vehicle

\section{Conclusions}

1. On the basis of the study methodological approaches to the implementation of control functions in the movement of vehicles are based on the use of automatic information and telecommunication systems. The basis of the developed technique is the joint use of probabilistic and statistical approach to assessing the effectiveness of the SAF and the general principles of system analysis.

2. A mathematical model of evaluating the performance of SAF with implementation of the functions of traffic control with the aim of improving road safety is presented.

3. The information-analytical system of interaction of "smart" onboard devices of vehicles and complexes of automatic photo-video fixation of administrative offenses is presented. This system makes it possible to establish the optimal level of development of multi-purpose complexes of automatic control of the movement of vehicles and, thus, to increase the efficiency of the functioning of land transport as a whole.

\section{References}

[1] GOST R ISO 14813-1-2011. Intellectual transport systems. Scheme of building intelligent transport systems architecture. Service domains in the field of intelligent transport systems, service groups and services [Intelligent transport systems. Scheme of building intelligent transport systems architecture. Service domains in the field of intelligent transport systems, groups of services and services]. 2201-03-01 M.:, 2012, p. 120. (Interstate Standard).

[2] Kerimov MA, Safiullin R.N., Means of photo and video recording of traffic violations: normative regulation and practice of application: monograph [Means of photo and video recording of road traffic violations: regulation and practice] M.A. Kerimov, R.N. Safiullin - Moscow: Direct Media, 2016, 355p.

[3] Noy. Harmonized research on ITS. - ITS Round Table, 18.02.2004, Geneva.

[4] GOST R 50856-96 "Meters of the speed of movement of vehicles radar. General technical requirements. Test methods. “- introduced 1997-01-01 M: State Standard of Russia; CPC Publishing house of standards, 1996. $16 \mathrm{p}$.

[5] Hiramatsu R. The Idea of «Driver in the Loop» in Advanced Driver Assistance Systems. - 12th ITS Informal Group Meeting within WP.29, 10.03.2006, Geneva.

[6] SAE J3016. Standard: Taxonomy and Definitions for Terms Related On-Road Motor Vehicle Automated Driving Systems. Issued: 2014-01-16 - SAE International Inc., 2014.

[7] Design Principles for Control Systems of ADAS. Informal document WP.29-160-15. - 160th WP.29 session, 25-28 June 2013, Geneva

[8] Tingvall $\mathrm{C}$ et al. The effectiveness of ESP (electronic stability programme) in reducing real life accidents. In: Proceedings of the 18th Experimental Safety of Vehicles Conference, Nagoya, 
Japan, 19-22 May 2003. Washington, DC, National Highway Traffic Safety Administration, 2003 [online][16.04.2019] Available at: http://www_nrd.nhtsa.dot.gov/pdf/nrd_01/esv/esv18/CD/Files/18ESV_000261.pdf.

[9] Minninhanov R.N. Ways of development of ITS in Kazan. - Collection of works of the International Academy of Transport №17. - M .: 2014, pp. 125-131.

[10] Kondratiev A. A. Barriers to ITS promotional processes. - Collection of works of the International Academy of Transport №17. - M .: 2014, pp. 89-91.

[11] Domke E. R. Investigation and examination of road accidents: a textbook for stud. Universities / E. R. Domsk. - 2nd ed. - M .: Publishing Center "Academy", 2012, 288 p.

[12] Kisulenko B.V. Automation of driving: development trends and conditions for implementation / Collection of works of the International Academy of Transport, No. 17, - Moscow: 2014, pp. 80-88.

[13] Degtyarev K.I. Classification of categorical structures of structural difficulties based on prototypes in simple complexes // Proceedings of the 10th International Conference on the Application of Fuzzy Systems and Soft Computing (ICAFS-2012) / Otv. Ed.: R. Aliyev, K. U. Bonfig, M. Jamshidi, J. Kapshik, V. Kreinovich, V., 2012, pp. 27-37.

[14] SAE J3016. Standard: taxonomy and definitions for terms related to automatic vehicle control systems on the road. Issued: 2014-01-16 - SAE International Inc., 2014.

[15] Principles of designing control systems ADAS. - Informal document WP.29-160-15. - 160th session of WP.29, 25-28 June 2013, Geneva.

[16] Ivnitsky V. Inappropriate risk. Determination of a given average daily level of speed for accelerated container trains due to technical failures / V. A. Ivnitsky // VNIIZhT Bulletin, №12, 2012, pp. 41-44.

[17] Joint dynamic actions for safe and energy-saving freight. - Informal document GRRF-76-43. 76th session of GRRF, February 17-21, 2014, Geneva

[18] Cooperative dynamic formation of platoons for sale and energy-optimized goods transportation. Informal document GRRF-76-43. - 76th GRRF session, 17-21 February 2014, Geneva.

[19] Safiullin R.N. Kerimov M.A. Evaluation of Functional Efficiency of Automated Traffic Enforcement Systems12th International Conference Organization and Traffic Safety Management in Large Cities, SPbOTSIC-2016. Transportation Research Procedia 20, pp. 288-294

[20] Safiullin R.N., Kerimov M.A. Intellectual airborne transport systems in road transport. Monograph, M.-Berlin: Direct Media, 2017, 354 p.

[21] Casti J., Kempf J., Duckstein L., Fogel M. Lake ecosystems: a polyhedral dynamics representation // Ecological Modelling. N 7, 1979, pp. 223-237.

[22] Griffiths H. B. Using mathematics to simplify Q-analysis // Environment and Planning. B: Planning and Design. No. 10(4), 1983, pp. 403-422.

[23] Degtiarev K. Y. Prototype-based categorization of structural complexity estimates of simplicial complexities// in: Proceedings of the 10th International Conference on Application of Fuzzy Systems and Soft Computing (ICAFS-2012) / Отв. ред.: R. Aliev, K. W. Bonfig, M Jamshidi, J. Kacprzyk, V. Kreinovich, W. Perdycz. Kaufering: b-Quadrat Verlag, 2012, pp. 27-37.

[24] Johnson J. H. Some structures and notation of Q-analysis // Environment and Planning. B: Planning and Design. No. 8(1), 1981, pp. 73-86.

[25] Johnson J. H. q-transmission in simplicial complexities // Int. J. Man-Machine Studies, No. 16, 1982, pp. 351-377. 